\title{
Intention to use a fully automated car: Attitudes and $a$ priori
} acceptability.

William PAYRE ${ }^{a, b}$, Julien CESTAC ${ }^{b}$ and Patricia DELHOMME ${ }^{b}$

a VeDeCom Institute

77 rue des chantiers, 78000 Versailles, France

b French Institute of Science and Technology for Transportation, Development, and Networks (IFSTTAR) France

Department of Planning, Mobilities, and Environment

Laboratory of Mobility and Behaviour Psychology

Correspondence should be addressed to:

William Payre

IFSTTAR

Planning Mobilities Environment Department

Laboratory of Mobility and Behaviour Psychology

25, allée des Marronniers - Satory, 78000 Versailles, France

Phone: + 33130843955

E-mail: william.payre@ifsttar.fr 


\section{Abstract}

If previous research studied acceptability of partially or highly automated driving, few of them focused on fully automated driving (FAD), including the ability to master longitudinal control, lateral control and maneuvers. The present study analyzes a priori acceptability, attitudes, personality traits and intention to use a fully automated vehicle.

421 French drivers (153 males, $M=40.2$ years, age range 19-73) answered an online questionnaire.

$68.1 \%$ of the sample a priori accepted FAD. Predictors of intention to use a fully automated $\operatorname{car}\left(R^{2}=.671\right)$ were mainly attitudes, contextual acceptability and interest in impaired driving (i.e. the two components of FAD acceptability), followed by driving related sensation seeking, finally gender.

FAD preferred use cases were on highways, in traffic congestion and for automatic parking. Furthermore, some drivers reported interest in impaired driving misuses, despite awareness of their responsibility for both the vehicle and the driving. These results are discussed regarding previous knowledge about acceptability of advanced driving assistance systems and consequences for the use of fully automated cars.

Keywords: fully automated driving; a priori acceptability; attitudes; intention. 


\section{Introduction}

\subsection{Partially and fully automated driving}

Automated driving aims specifically at increasing road safety, reducing traffic congestion, gas emissions and fuel consumption (European Commission, 2011). Thus research concerning civil vehicle automation is crucial. It started in Europe in the late $80^{\prime}$ s with the European EUREKA Prometheus project which contributed to the conception of the first driverless cars. Since then, many automated prototypes had been constructed and had driven efficiently on different kind of roads in a highly automated mode i.e. mastering both longitudinal and lateral control with few supervisor interventions. For example, the Defense Advance Research Projects Agency (DARPA, 2005) consisted of a 132 miles race in the desert completed by autonomous cars. The Citymobil research, development and demonstration project aimed at integrating automated transport systems in the urban environment (van Dijke \& van Schijndel, 2012). Interest in automated driving still grows, as shown by the $9^{\text {th }}$ ITS European Congress (2013) which organized a special interest session dealing with highly automated vehicles, highway trucks and cars platooning, as well as automated urban transportation.

A distinction must be made between the different levels of automation in driving. Regarding partially automated cars, the terminology is varied: automated driving, partially automated driving and highly automated driving (e.g. Jamson, Merat, Carsten \& Lai, 2013). Concerning public policies, the National Highway Traffic Safety Administration (NHTSA) provided a framework describing five different levels of driving automation (NHTSA, 2013), ranging from 0 (i.e. No-Automation) to 4 (i.e. Full Self-driving Automation). Fully automated driving (FAD) refers to a vehicle able to drive autonomously without any intervention from the driver, or anyone else in the vehicle, as soon as the fully automated mode is activated (e.g. NHTSA's levels 3 and 4). In a fully automated car, longitudinal control (i.e. headway between vehicles and speed), lateral control (i.e. position in the lane) and maneuvers (such as overtaking and braking) are handled by the system, not by the driver. One of the most famous FAD project concerns Google's self-driving car, considered level 3 - limited self-driving 
automation by the NHTSA. This car is able to drive autonomously in fully automated mode in Nevada and California since 2011 (Guizo, 2011), albeit the presence of an engineer is required by law at the driver's seat. Renault announced in 2013 that they would commercialize before 2020 a car with a driving delegation device efficient up to $30 \mathrm{~km} / \mathrm{h}$ (Bouteiller, 2013). Concerning medium speed automation, Audi presented during the International CES 2014 in Las Vegas a prototype of the Piloted Driving system, which allowed drivers to use this system in heavy traffic, up to $40 \mathrm{mph}(64 \mathrm{~km} / \mathrm{h})$. This device would be available by 2016 .

Nowadays, drivers have the opportunity to buy new cars with different automated driving features, such as Adaptive Cruise Control (ACC, see Saad, Hjälmdahl, Cañas, Alonso, Garayo, Macchi et al., 2004 for a review on the device), Lane Keeping System (LKS), or even Stop and Go device which matches the speed of the car in front in low speed traffic and can also stop and restart the vehicle by itself. These devices make the driving partially automated. Indeed, the driver is assisted, and sometimes substituted, by an electronic system to perform some of the driving tasks, such as mastering longitudinal and lateral control (ACC, LKS), threshold and cadence braking (ABS), or even automatic braking while skidding (ESC).

Since fully automated cars are not commercialized yet, it is important to examine acceptability, attitudes and drivers' intentions toward FAD. Regarding these topics, the highest levels of driving automation have not been entirely addressed yet. Hence, theory about intention, behavior and technology acceptability will be introduced, as well as previous research concerning partially automated driving that focused on attitudes, acceptability and behavioral adaptation. Afterward, the results of the empirical study on the intention to use FAD will be presented.

\subsection{A priori acceptability, attitudes and intention to use automated driving}

A priori acceptability of a technology can be defined as the evaluation of that technology before having any interaction with it. Technology acceptability deals specifically with perceived usefulness and perceived ease of use (Davis, 1989). Technology a priori acceptability should be addressed considering the evaluation of the technology itself and the methodology used to evaluate 
it (Bagozzi, 1981), as well as its potential uses, which is possible (Laurencin, Hoffman, Forest \& Ruffieux, 2004; Terrade, Pasquier, Reerinck-Boulanger, Guingouain, \& Somat, 2009).

The Technology Acceptance Model (TAM) (Davis, Bagozzi, \& Warshaw, 1989) adds more precision on the way to evaluate a technology. It postulates on the one hand that intentions to use a technology have an incidence on usage behavior, and on the other hand that perceived ease of use and perceived usefulness determine intention to use. Moreover, behavioral intention can be predicted by attitudes (Albarracin, Johnson, \& Zanna, 2005; Fishbein \& Ajzen, 1975). Attitudes can be defined as a psychological tendency that is expressed by evaluating a particular entity with some degree of favor or disfavor (Eagly \& Chaiken, 1993, p. 1). It seems reasonable thus to expect that the intention to use a technology/object could be predicted to some extent by users' attitudes and by its a priori acceptability, especially because a priori acceptability and attitudes are correlated (Parasuraman, Singh, Molloy, \& Parasuraman, 1992).

Attitudes are globally positive toward simulated partially automated driving systems (Nilsson, 1995; Stanton, Young, \& McCaulder, 1997; de Waard, ven der Hulst, Hoedemaeker, \& Brookhuis, 1999). In addition, delegating driving can be appealing when a journey is considered monotonous or unpleasant (Fancher, Ervin, Sayer, Hagan, Bogard, Bareket et al., 1998), confirming that use cases have a major role in Advanced Driving Assistance Systems (ADAS) acceptability. Indeed, traffic congestion and highways seemed to be situations in which using partially automated driving would have benefits on driving comfort, according to studies on ACC (Saad \& Villame, 1996). Finally, men are more inclined than women to use technology (Venkatesh, Morris, \& Ackerman, 2000). Nonetheless, the authors did not report the effect of age on technology acceptability in this study.

Furthermore, ADAS that decrease control on driving (e.g. decision making) may have less chance to be accepted by drivers (van der Laan, Heino, \& de Waard, 1997). Indeed, although ADAS are evaluated positively as useful and safe, drivers have a negative judgment on people choosing to use such driving assistance systems because they think that they are considered drivers with poor skills (Lefeuvre, Bordel, \& Guingouain, 2008). This contrast might be in conflict with the development 
of automated driving systems because in the partially automated mode, the driver does not directly control the classic driving tasks such as navigation, control or hazard identification (Stanton, Young, Walker, Turner, \& Randle, 2001). This could lead to a rejection of driving assistance technology, and stresses the paradox between positive subjective evaluation of a technology and the weak intention to use it. However, the fully automated level of driving is able to substitute the driving system for the driver; he/she might then think he/she is not assisted but substituted by the automated driving system. Thus, being substituted might lead to either rejection or approval of the automated driving system, depending on the personality traits of the driver.

\subsection{Behavioral adaptation, personality traits and new driving technology}

Among studies on behavioral adaptation to ADAS, one of the main findings is that locus of control and sensation seeking are personality traits which could have an influence on driving behavior when using ADAS (Rudin-Brown \& Noy, 2002; Rudin-Brown \& Parker, 2004; Stanton \& Marsden, 1996; Ward, Fairclough, \& Humphreys, 1995).

Locus of control is defined as a personality trait that echoes the extent to which a person believes he or she can control events that affect him/her (Rotter, 1966). Someone who believes he/she can control events has an internal locus of control, whereas those who do not believe it are external. Concerning partially automated driving and locus of control, overconfidence is more salient for drivers with an external locus of control than those with an internal locus of control; this result has been observed on a simulator but not on a test-track (Rudin-Brown \& Noy, 2002). Yet, locus of control was not affected by simulated partial automation (i.e. ACC, Stanton \& Young, 2005), whereas locus of control did increase external drivers' reaction time to ACC failure compared to internals in Rudin-Brown and Parker's experiment on a test-track (2004). It might be easier for external drivers to trust automated driving system, considering they rely less on their own driving skills than internals (Rudin-Brown \& Noy, 2002). In order to measure driving locus of control, Montag and Comrey (1987) developed a driving internality-externality scale, with two independent (not bipolar) dimensions. Externals are expected to prefer FAD more than internals. 
Sensation seeking is defined as a trait describing the tendency to seek novel, varied, complex and intense sensations and experiences and the willingness to take risks for the sake of such experience (Zuckerman, 1994). High sensation seeking is positively correlated with risk taking behavior, including driving (Jonah, Thiessen, \& Au-Yeung, 2001; Zuckerman, 1994). The drivingrelated sensation-seeking scale (DRSS) (Taubman, Mikulincer, \& Iram, 1996, adapted by Delhomme, 2002) has also been positively correlated with driving risky behavior (Cestac, Paran, \& Delhomme, 2011; Delhomme, Verlhiac, \& Martha, 2009; Yagil, 2001). Thus, high sensation seekers are expected to intend to use a fully automated car more than low sensation seekers, in order to experience novelty and adventure. However, delegating driving may lower thrill experience while driving. It has been shown that when using an ACC device, high sensation seekers drive on average faster, with shorter headways between vehicles and make stronger braking (Hoedemaeker \& Brookhuis, 1998; Ward et al., 1996). Thus, high sensation seekers might adapt their behavior while being driven by an electronic system in their own car by being less careful.

Behavioral adaptation using ADAS or different levels of automated driving could be explained by the will to maintain a certain level of task difficulty (Fuller, 2005). Indeed, driving task difficulty, defined as the dynamic interaction between the determinants of task demand and driver capability, might be challenged when delegated to an electronic system, as it is in FAD. This perceived substitution in driving activity could lead operators to redefine driving activity. As their driving capability is no longer challenged, they could aim at realizing another activity (e.g. reading the newspaper, checking emails on a smartphone, etc.), giving up supervising whether needed or not, or even using FAD while they should not (e.g. while impaired). Giving up supervising or using FAD while impaired could enhance the difficulty of the last driving task left when using FAD: manual control recovery.

\subsection{Objectives}

Studying specifically FAD was decided because research on behavior toward automated driving had essentially focused on partial automation (Özkan, Lajunen, \& Kaistinen, 2005; see Saad et 
al., 2004; Stanton \& Young, 1998, 2005), especially on the ACC and more generally on level 1 and 2 of NHTSA's framework. The objectives of the study are to evaluate if drivers have the intention to use FAD (i.e. NHTSA's level 3 of automation), and if this intention to use FAD can be predicted by a priori acceptability, attitudes, personality traits and behavioral adaptation to automated driving. Considering tools evaluating drivers' attitudes toward this technology do not exist yet, two pilot studies were conducted to explore motivations, attitudes and intentions toward FAD. This iterative process is usual in a poorly explored field and does not need large samples because the pilot studies only aim at increasing the validity of the tool (Delhomme \& Meyer, 2002; Robson, 1993).

\section{Pilot Studies}

The main goal was to ask drivers questions on FAD, according to their driving experience and the knowledge from the literature review.

\subsection{First pilot study method}

\subsubsection{Participants}

Five semi-directive interviews were conducted in order to collect information about intention to use and acceptability toward FAD. Participants ranged from expert to neophyte concerning automated driving knowledge. All of them were men.

\subsubsection{Procedure}

The semi-directive interview framework was based on a state of the art concerning automated driving, automation, and driving habits. Information based on constructors' reports and exhibitions were also gathered.

Participants to this pilot study were interviewed face-to-face. Data collecting took from 30 to $60 \mathrm{~min}$. 


\subsubsection{Measures}

A short description of a fully automated car was given to the participants along with some use cases and examples: "An automated car is a vehicle which driving functions are handled by an in board computer. It is able to master the speed, headways, braking and maneuvers of the vehicle. It is designed to be used by all kind of drivers". They were told that in such a car, they were still responsible for both the driving and the vehicle. This description refers to NHTSA's level 3, limited self-driving automation, as drivers are expected to be available for occasional manual control.

Ten questions were formulated to the participants. Firstly, participants were asked about their interest in a fully automated car. Then, the questions concerned the context in which they would use it, what they would expect from that kind of technology and if they would feel responsible for the car and the driving while cruising in automated mode. Finally, questions about impaired driving and the intention to use FAD were asked.

\subsubsection{Results}

Interviews gave clues about the favorable conditions that would lead drivers to accept automated driving. The driving environment is a recurring element that appeared in the verbatim, e.g. I will not use such a device in a city (i.e. built-up areas) because it is too risky, particularly when children cross the streets (observed five times out of five interviews); I might use driving automation for a long journey, when driving is not stressful (observed four times). Questions about impaired driving in a fully automated car were also asked. They dealt with alcohol, drug use, medication that could affect driving abilities and tiredness. Two out of five interviewees declared they would have a temptation to use FAD while being over the alcohol limit, two out of five declared they would use it after taking side-effects medication: Taking such medication and using fully automated driving would be attractive. I used to have some health problems and I had to take public transportation. The disadvantage is that you are still responsible for the driving. 


\subsection{Second pilot study method}

Based on the analyze of the interviews from the first pilot study, questions were formulated about intention to use and a priori acceptability of FAD, leading to a first questionnaire including 39 items.

\subsubsection{Participants}

In the second pilot study, 45 participants answered the questionnaire, $52.2 \%$ of them were women. Mean age of the sample was 33.6 year-old, $\min =19 ; \max =68$. On average, they had held their driving license for 15.4 years, and had driven for $194 \mathrm{~km}$ the previous week before filling the pilot questionnaire.

\subsubsection{Procedure}

Answers were all collected with a paper version of the questionnaire. Participants were not observed while doing it. A short description of a fully automated car (the same as in the first pilot study) was given to them. They were told they would be responsible for both the driving and the vehicle. Approximately $15 \mathrm{~min}$ were needed to answer the questionnaire.

\subsubsection{Measures}

A 7-point Likert scales was used, ranging from 1: I strongly disagree to 7: / strongly agree. The seven themes of the questionnaire were:

1. The level of automation they wanted to set: e.g. I would like to choose which devices are automated, $M=6.45, S D=.59, \min =5, \max =7$;

2. Intention to use FAD depending on the driving environment: e.g. If driving was boring to me, I would rather delegate it to the automated driving system instead of doing it by myself, $M=5.02$, $S D=1.88, \min =1, \max =7 ;$ I would rather use the automated driving system on the highway than driving by myself, $M=5.31, S D=1.95, \min =1, \max =7$; 
3. The situations in which they would prefer to recover control from the automated pilot: e.g. I would like to recover control from the automated pilot if I did not like the way it drives, $M=6.38, S D=$ $1.07, \min =1, \max =7$

4. Interest in using automated driving while impaired: e.g. I would delegate the driving to the automated driving system if: I was over the drink driving limit, $M=6.11, S D=1.67$, $\min =1$, $\max =7$; I was tired, $M=5.38, S D=1.87, \min =1, \max =7$; I took medication that affected my ability to drive, $M=$ $5.42, S D=1.97, \min =1, \max =7$;

5. Intention to use the automated car with other passengers on board: If I had passengers in my automated car, I would rather drive by myself than delegating to the automated driving system $M=4.37, S D=1.65, \min =1, \max =7$;

6. Their estimation in hours on the extra time needed to learn how to drive an automated car: According to me, how much time would I need to learn how to drive an automated car? $M=9.2$, $S D=9.5, \min =1, \max =50$

7. The following socio-demographic variables were registered: age, gender, academic degree, profession, how long they had held their driving license and how far they had driven the previous week of the study.

\subsubsection{Results}

An exploratory factor analysis was led, resulting in extracting eleven factors. An oblimin rotation was applied, and the chosen extraction method was principal component analysis. The first two factors were selected because they explained respectively $25 \%$ and $12 \%$ of the variance. These two sets of items made sense and were coherent for each factor. Redundant items were excluded as well as items with low factor loadings. Finally, seven items were identified according to their high factor loadings (>.65) on their respective dimensions. A second factor analysis, with again a principal component analysis extraction and oblimin rotation, was led on these seven items. Two factors were selected because their eigenvalues were above one. The first dimension ( $42 \%$ of the variance) referred to the contextual acceptability of an automated car system ( $\alpha=.83$ ), (four items): 
1. I would rather keep manual control of my vehicle instead of delegating it to the automated driving system in every occasion, $M=3.8, S D=2.04$, $\min =1$, $\max =7$;

2. The automated driving system would provide me safety compared to manual driving, $M=3.67, S D=1.7, \min =1, \max =7$;

3. If driving was boring to me, I would rather delegate it to the automated driving system instead of doing it by myself, $M=5.02, S D=1.88, \min =1, \max =7$;

4. If I had passengers in my automated car, I would rather drive by myself than delegating to the automated driving system, $M=4.37, S D=1.65, \min =1, \max =7$.

The second dimension ( $25 \%$ of the variance) referred to the interest in using driving automation while impaired $(\alpha=.72)$, (three items):

1. I would delegate the driving to the automated driving system if I was over the drink driving limit, $M=6.11, S D=1.67, \min =1, \max =7$;

2. I would delegate the driving to the automated driving system if I was tired, $M=5.38$, $S D=1.87, \min =1, \max =7$

3. I would delegate the driving to the automated driving system if I took medication that affected my ability to drive, $M=5.42, S D=1.97, \min =1, \max =7$.

The sample was small $(N=45)$, and the age proportion was unbalanced, $M \hat{\rho}=30.7, M P=36.6$, however this analysis was conducted only to select the most relevant items.

\section{Main study}

\subsection{Hypotheses}

Results from the two pilot studies and the literature review presented above led to build the questionnaire and to formulate the following hypotheses. The present study aimed at exploring two different issues concerning FAD. The first one was: to what extent would drivers a priori accept FAD? If they did, to what extent would they intend to use such a system? The first hypothesis was that 
drivers would a priori accept FAD because of its features (e.g. longitudinal control and lateral control); it was expected that FAD would be considered more useful than manual driving ( $\mathrm{H} 1)$, as shown by Hoedemaeker and Brookhuis (1998) and Hoedemaeker and Kopf (2001), even if the authors used partial automation. Attitudes were also expected to predict the intention to use a fully automated car ( $\mathrm{H} 2)$.

Moreover, the authors hypothesized that personality factors such as sensation seeking and locus of control would be related to the intention to use it. Thus, it is supposed that high sensation seekers would intend to use this technology more than low sensation seekers (H3a) (Rudin-Brown \& Parker, 2004) and that drivers with external locus of control would intend to use it more than those with internal locus of control (H3b), as shown by Rudin-Brown and Noy (2002) and Rudin-Brown and Parker (2004). The fourth hypothesis was that the will to use a fully automated car would depend on the driving environment, according to the results of the first pilot study. Drivers were expected to be more interested in FAD on highways, in traffic congestion and when driving is monotonous, than in built-up areas ( $\mathrm{H} 4)$. Furthermore, drivers were expected to be interested in using a fully automated car while impaired, again according to the results of the first pilot study and to task difficulty homeostasis theory (H5). Finally, it was hypothesized that men's attitudes toward FAD would be more positive than women's, and also that they would intend to use it more than women, as shown by Venkatesh et al. (2000) (H6).

These hypotheses were tested using an online questionnaire.

\subsection{Method}

\subsubsection{Participants}

A sample of 421 drivers (153 males), took part to the study. Among them, 62 participants did not answer entirely the questionnaire. Notwithstanding, they were included in the analysis because they completed entirely one or several sections before quitting. Mean age of the sample was 40.2 , $S D=15.9, \min =19, \max =82$. They reported having their driving license for 20.8 years on average, $S D=$ 
$15.8, \min =0, \max =63$, and driving an average of $250 \mathrm{~km}$ the last week before they filled the questionnaire, $S D=305.6, \min =0, \max =2000$.

\subsubsection{Procedure}

The questionnaire was broadcast to mailing lists dealing with ergonomics, psychology, engineering as well as people unfamiliar with driving automation field. Participants were told that the driving license was required to take part in the study. The questionnaire was uploaded on the internet, using an online survey tool.

\subsubsection{Measures}

The questionnaire was presented as a survey aiming at evaluating behaviors toward driving automation. In the first out of six sections, a short and simple description of a fully automated car was presented, the same as in the pilot study, along with some examples of concrete use cases. Drivers were told to imagine themselves driving such a car in automated mode: Imagine yourself making a trip. You are the driver in your own car which is equipped with an automated driving system. They were also told that they were still responsible for the car and for the driving. The questionnaire consisted of the two FAD a priori acceptability dimensions extracted from the second pilot study, and an adaptation of Montag and Comrey driving internality-externality scales. In addition to these scales, participants' intention to use FAD, attitudes toward FAD, driving-related sensation-seeking scale score (DRSS) as well as demographics were measured.

In the second section, features of the fully automated car were described along with usecases. Participants were informed about the mandatory responsibility for the driving and the vehicle. They were asked if they understood what was FAD and if they had their driving license. If they did, they were able to start the first section of the questionnaire. A Likert scale (1 referring to "I do not agree at all", 7 referring to "I totally agree") was used for the different scales and items presented.

In the third section, 7 questions were presented in a random order to measure a priori acceptability. As in the pilot study, the factor analysis revealed two dimensions from this set of 
questions, composing the FAD acceptability scale: contextual acceptability toward FAD, $\alpha=.72$, and interest in using FAD while impaired, $\alpha=.89$. The internal consistency of the FAD acceptability scale is good, $\alpha=.77$

The fourth section, contained the driving internality, $\alpha=.87, M=6.4, S D=3.7$ and the driving externality, $\alpha=.75, M=5.8, S D=0.74$, scales adapted from Montag and Comrey (1987). Each scale consisted of 15 items.

In the fifth section, they filled questions about intention to use automated driving, how much they would spend to buy an automated driving device (i.e. open-ended question), what kind of road or traffic environment they would prefer to use the system, and finally their attitudes toward automated driving (e.g. I consider fully automated driving as unpleasant vs. pleasant, useless vs. useful, dangerous vs. sure). The three items on attitudes were merged into one dimension, $\alpha=.88, M=$ $4.56, S D=1.49$.

In the sixth section, they filled the DRSS, $\alpha=.75$. Confirmatory factor analyses confirmed the unidimensionality of this scale.

In the last section, they answered socio-demographic questions: gender, age, year of driving license acquirement, kilometers driven last week, and extra-hours estimated to learn automated driving.

\subsection{Results}

A confirmatory factor analysis was conducted on the FAD acceptability scale, in order to test the two-factor structure found in the pilot study: intention to use FAD while impaired and contextual acceptability. This structure was confirmed, and the model showed acceptable fit $(N F I=0.96$, RSMEA = 0.07, CFI= 0.97). Indeed, the NFI specifies a good fit when above 0.95 (Jöreskog and Sörbom, 1989), the value of the RMSEA is acceptable when below 0.08 (Browne and Cudeck, 1989), and a value of $\mathrm{CFI} \geq 0.95$ is recognized as indicative of good fit (Hu and Bentler, 1999). The two dimensions were positively correlated $r=.38$ (see Fig. 1). 
Insert Figure 1 about here

The descriptive analysis of the study's results is presented in the next section. The linear regression analysis aiming at explaining the intention to use FAD will be described afterward.

\subsubsection{Descriptive analysis}

Overall, $68.1 \%$ of the participants scored above 4 (i.e. the median point of the 7-point likert scale) on the FAD acceptability scale. Concerning the two dimensions of this factor, $70.6 \%$ of the participants scored above 4 on the interest in using FAD while impaired dimension, and $52 \%$ scored above the median on the contextual acceptability dimension. Most of them were interested in using a fully automated car, $52.2 \%$ scored above the median of the scale, $M=4.46, S D=1.84$, $\min =1$, $\max =$ 7; nevertheless, they were not quite ready to buy one yet, $M=3.54 ; S D=1.98, \min =1, \max =7$ (see Table 1). Concerning the willingness to pay for a fully automated car, when participants envisaged to buy one ( $78 \%$ of the sample), they were ready to spend on average $1624 €, S D=2112, \min =0^{1}, \max =$ 10000. Attitudes toward FAD were rather positive, $M=4.56, S D=1.49, \min =1, \max =7$.

Participants estimated they would need almost 7 extra hours on average to learn how to drive a fully automated $c a r, M=6.92, \min =0, \max =72$. This is two hours less than what was found in the pilot study. They had held their driving license for more than 20 years on average when they answered the questionnaire in April 2013, $M=20.9, S D=15.8, \min =0, \max =63$.

\section{Insert Table 1 about here}

As expected, there was a significant correlation between contextual acceptability and attitudes, confirming results from previous research (Parasuraman et al., 1992). An effect of gender on the intention to use and to buy an automated car was also observed (see Table 1). Men wanted to use it more than women, and they were more inclined to buy one. Men would also be more

\footnotetext{
${ }^{1}$ Paying $0 €$ to get a FAD system in addition to the price of a regular car could mean that participants considered this device should be included in the basic features as it is, for example, for power-assisted steering.
} 
interested in using it while impaired. They accepted more FAD than women, and had more positive attitudes toward it. Except for the gender, low correlations were found with the adaptation of Montag and Comrey scales. There were low positive correlations with driving internality and both acceptability and attitudes (see Table 2 ), $r=.12$. Driving externality was slightly correlated with the DRSS, $r=.13$. High significant correlations between attitudes toward FAD and both intention to use and intention to buy a fully automated car (see Table 2) were found. Finally, a significant correlation between DRSS and interest in using FAD while impaired was found, $r=.1, p<.05$.

\section{Insert Table 2 about here}

Concerning uses of FAD, participants said they would use it $67.2 \%$ of the time to undertake parking maneuvers, $S D=36.6,62.3 \%$ of the time on highways, $S D=34.4$, and $60 \%$ of the time in traffic congestion, $S D=38.9$. FAD in built-up areas would be used $29 \%$ of the time, $S D=32.5$.

\subsubsection{Regression analysis}

A hierarchical linear regression was performed to test which were the predictors of intention to use an automated car. The dependent variable was the item: "I would be ready to use an automated car instead of a regular car". Three steps were used to introduce the 7 independent variables of the analysis: gender, age, and DRSS score for the first step, interest in using FAD while impaired and contextual acceptability for the second step, and finally attitudes toward FAD for the third step.

The model accounted for $67.1 \%$ of the variance of the intention to use an automated car (see Table 3). Simple effects analyses showed that intention to use an automated car was reliably affected by the attitudes toward driving automation, $b=0.616, p<.001$, contextual acceptability, $b=0.238$, $p<.001$, and sensation seeking, $b=0.067, p<.05$. An effect of the gender only in the first step, $b=-$ $0.161 p<.05$ was also observed, meaning men were a bit more interested in using such a car than 
women. Notwithstanding, when contextual acceptability was included in the regression, gender became no longer significant. There was no significant effect of age. Moreover, interest in using driving automation while impaired explained a part of intention to use FAD when it was included in the second step of the regression, $b=0.11, p<.05$. Nonetheless, this effect became insignificant as soon as the attitudes toward driving automation were introduced in the third and last step. Driving related sensation seeking explained a part of the variation in every step of the analysis. This part was more important in the first step, $b=0.136, p<.05$ than in the last step, $b=0.067, p<.05$.

Insert Table 3 about here

\section{Discussion}

Fully automated driving (FAD) is something rather new in France, and few people had interactions with that kind of technology. For this reason, this research aimed at predicting intention to use such a vehicle, according to a priori acceptability, attitudes, gender, and personality traits. As expected, slightly more than two thirds of the drivers from the sample would a priori be favorable to use FAD (i.e. scored above the median point of the likert scale) (H1). This result was congruent with those found previously concerning ADAS and partial automation (Nilsson, 1995; Saad \& Villame, 1996; Stanton et al., 1997; de Waard et al., 1999), except that drivers were asked to answer according to a description of FAD. At last, it is possible that drivers could have a negative judgment on people using FAD (Lefeuvre et al., 2008), and this should be tested in further studies.

Furthermore, uses and attitudes toward this new automobile technology were underlined. As frequently found in the field of driving behavior, a strong positive correlation between attitudes and intention to use FAD was observed $(\mathrm{H} 2)$. Intention to use FAD was partially $\left(R^{2}=0.67\right)$ explained by attitudes $(b=0.62)$, contextual acceptability $(\beta=0.24)$ and the DRSS $(b=0.067)$. Interest in using FAD while impaired, gender and age were not significant in the last step of the linear regression.

As expected, the higher the driving-related sensation-seeking, the more drivers intended to use FAD (H3a). Nevertheless, the DRSS (7 items) did not allow telling if this result was linked to 
adventure or novelty seeking, disinhibition or boredom, according to Zuckerman's sensation-seeking scale (1994). For instance, one could think that novelty seeking would increase intention to use FAD in the first place, but once used to FAD, drivers may not feel novelty anymore. Moreover, using FAD in the long run might be in contradiction with the pleasure of driving. It could also be assumed that avoiding boredom in traffic congestion or on the highway by performing another task might appeal to sensation seekers as well. Nonetheless, these detailed relations between sensation-seeking dimensions and intention would need another study to be assessed.

Unexpectedly, no correlations were found between the external driving locus of control and neither a priori acceptability nor attitudes toward the automated car ( $\mathrm{H} 3 \mathrm{~b})$. This might be explained by the insignificant correlation found between the two internality-externality scales, whereas Montag and Comrey (1987) found a negative one, $r=-.18$. It is also possible that it came from the scale's adaptation in French. Moreover, externals might need to use this kind of technology to evaluate the system's skills compared to theirs. This should be addressed in future research concerning FAD.

Intention to use a FAD system varied according to the use cases $(\mathrm{H} 4)$. Indeed, the preferred situations for using a fully automated car were monotonous (e.g. highways) or stressful driving conditions (e.g. traffic congestion). FAD was perceived positively when related to these use-cases. This result was congruent with studies dealing with ACC in monotonous driving situations (Fancher et al., 1998; Saad \& Villame, 1996): FAD, by controlling longitudinal, lateral control and maneuvers would make monotonous or stressful driving less unpleasant. Nevertheless, in the present study FAD would be less often used in built-up areas - which could be considered a stressful situation - maybe because drivers felt more confident in their own skills when road hazards were considered to happen more frequently. Level of stress and difficulty might be more important in built-up areas than in other use cases. This result echoed the interviews from the first pilot study. Manufacturers should be interested in these results because low-speed automated driving systems that exist nowadays are designed to be used in built-up areas or in traffic situations. As said for a priori acceptability and 
intention to use a fully automated car, drivers' intention to use such a system might vary with experience and use of the system.

Almost $71 \%$ of the participants declared they would be interested in using FAD while impaired (H5). This result could seem surprising compared to manual driving. Indeed $45 \%$ of French car drivers declared having driven after having drunk, even a small amount of alcohol in study's past month; in Europe, on average $31 \%$ of car drivers drunk a small amount of alcohol before driving (Cestac \& Delhomme, 2012). It can be assumed that FAD was seen as a transportation facilitating mobility of impaired drivers, although being physically and psychologically able to drive is required by the Vienna Convention (1968). This result confirmed the link between the DRSS and risky-driving, and was congruent with results found in previous studies between high sensation seeking and driving risk-taking behavior (Cestac, Paran \& Delhomme, 2011; Delhomme, Verlhiac \& Martha, 2009; Yagil, 2001). Moreover, it is possible that this result would be related to behavioral adaptation. Indeed, using a FAD system might inhibit the feeling of driving, decreasing the need of being in control and being responsible for the vehicle. Therefore, participants may anticipate an opportunity to drive although impaired or even an opportunity to perform a task unrelated to driving when using automated driving e.g. reading the newspaper or taking care of younger passengers. This result highlighted the importance of making aware both manufacturers and drivers on the potential risk of FAD misuses. Furthermore, it can be argued that other kinds of drivers could be tempted by FAD misusing, e.g. when the driving license is no longer available or when drivers are disabled. Indeed, FAD could be a solution for individuals who cannot drive anymore, as suggested by participants in the pilot studies (i.e. section 2.1.4.). For example, a medical authorization could be delivered to enable disabled people to use FAD in specific conditions, in order to increase their autonomy if policies allow it.

Compared to women, men had more positive attitudes toward FAD and wanted to both use and buy it more. This result is in line with what was expected (H6). However, when contextual 
acceptability and interest in using FAD while impaired were added in the regression, gender became insignificant.

Questions about the desired level of automation asked to the participants of the second pilot study did not have straightforward results, maybe because participants could not imagine accurately the possible interactions with the automated driving system. It can be assumed that those results pointed out the difficulty for drivers to envision what it would be like to use an automated car without experiencing it. Difficulties to evaluate a priori acceptability were here emphasized. Indeed, considering that trust in an ADAS depends on the perceived performance and reliability by users (Maltz, Sun, Wu, \& Mourant, 2004 ; Moray, Inagaki, \& Itoh, 2000 ; Riley, 1994), trust in automation could have had an influence on the evaluation. FAD acceptability might be better evaluated after experiencing it, (i.e. acceptance) or seeing it performing a trip, which was not the case in this study. Further research should consider adding pictures, videos or real exhibitions to evaluate this uncommon technology a priori acceptability.

Drivers might have different attitudes and intention to use after experiencing and using FAD. Indeed, it had been shown that practicing regularly a new technology might lead to automation complacency bias (Terrade et al., 2009), defined as a psychological state characterized by a low index of suspicion (Wiener, 1981). In other words, when someone is assisted by an automated device and has to switch from performing a task himself or herself to monitoring the operation, he or she can face difficulties to react efficiently when the device fails (Parasuraman et al., 1993). Further research should thus take into consideration evaluating attitudes and intention before, during and after experiencing FAD. Using a driving simulator to evaluate these dimensions should be an interesting alternative.

Finally, implications of this research are varied. First of all, the interest in using FAD while impaired probably means that drivers are not quite ready to stay in the control loop in fully automated mode (Kaber \& Endsley, 1997). Indeed, if drivers are released from the driving task, they may be tempted to also give up supervising, or even to consider they are no longer responsible for 
neither the car nor the driving. It seems clear this device will be used to substitute drivers and let them realize another task. This is coherent with the findings found by van Driel, Hoedemaeker and van Arem (2007), concerning traffic congestion: "drivers do not make a problem of handing over control to the car during such an uncomfortable driving task". Driving could thus be considered a secondary task when it is delegated, as the limit between being a passenger or a driver is blurry. Besides, if responsibility is not clearly attributed, one can consider being able to use FAD in spite of being impaired or disabled. The second implication deals with the consequences of being out of the control loop or impaired while using FAD. Difficulties to recover manual control, whether happening in an emergency scenario or not, should be a problem and highlight an important matter of performance. Indeed, drivers being out of the loop are exposed to mental underload, which increases the difficulty to recover manual control, particularly in hazardous and emergency situations (Young \& Stanton, 2007). As a matter of fact, recovering manual control while being out of the control loop might be a difficult maneuver, even if drivers are not impaired. Public policies should take into consideration these results to define clearly what the necessary conditions to use FAD are. Manufacturers might prevent impaired driving by making drivers' status monitoring devices a standard in fully automated cars, as some of them have already included such devices in their prototype (e.g. Audi's Piloted Driving system).

In order to raise intention to use FAD, one should evaluate attitudes toward FAD because they were the main predictors of its intention to use. Moreover, we assumed that intention to use FAD would be more important if drivers were presented NHTSA's level 4 of automation, because they would not have to supervise the driving, implying no responsibility for it. According to the results, drivers were not quite ready to endorse responsibility for the driving, considering their interest in using it while impaired. Therefore, it could be argued that automated vehicles should be able to drive autonomously without requiring any intervention from the driver, as human error is considered the main cause in both roadway and aircrafts crashes. Nevertheless, if operators make errors when using 
automated systems, automation is also exposed to designers' errors (Bainbridge, 1983; Parasuraman \& Riley, 1997).

\section{Study limitations}

Social desirability bias in a questionnaire refers to respondents' perception of what is correct or socially acceptable (Maccoby \& Maccoby, 1954). However, in this survey, participants were not observed while answering the online questionnaire, which might lessen this effect (Leggett et al., 2003). Generalizing the results should be done with caution because the sample consisted of an unbalanced gender proportion. Moreover, the questionnaire was partially broadcast on specific mailing lists, and it was not possible to determine the proportion of this particular population. Usually familiar with the field of human-machine interaction, these individuals might have more positive attitudes toward FAD. Nevertheless, no effects of the academic degree were observed on the results. Next research on FAD acceptability should control this sampling bias anyway.

In addition, participants' interest in technology was not evaluated in this study. Technophiles might be more enthusiastic about envisioning driving in a fully automated car than others.

\section{Conclusions}

Concerning a priori acceptability of FAD, two thirds of the sample had a mean score greater than the median point of the scale. Even though participants did not try such a car, they had positive attitudes toward it. However, intention to use FAD was different from one driving environment to another. It was also closely linked to the attitudes toward such a system, the contextual acceptability, the interest in using it while impaired and finally the DRSS score.

Furthermore, contextual acceptability explained a part of intention to use that was not explained entirely by attitudes. Further research should include the pleasure of driving when addressing FAD acceptability.

Overall, the present study provided a tool to assess FAD acceptability in future research. Moreover, attitudes and a priori acceptability appeared to be complementary concepts when 
evaluating intention to use FAD. Finally, manufacturers should be aware that there is a potential risk of misuse that should be taken into account when developing and designing FAD.

\section{Acknowledgements}

This work has been carried out within the framework of the VeDeCoM Institute, which contributed to support the study. We also would like to thank the two reviewers and the guest Editor who contributed to ameliorate this paper.

\section{References}

Albarracín, D. E., Johnson, B. T., \& Zanna, M. P. (2005). The handbook of attitudes. Lawrence Erlbaum Associates Publishers.

Bagozzi, R. P. (1981). Attitudes, intentions, and behavior: A test of some key hypotheses. Journal of personality and social psychology, 41(4), 607.

Bainbridge, L. (1983). Ironies of automation. Automatica, 19(6), 775-779.

Boutelier, J. (2013, December). Next Two: Renault lancer sa voiture robot avant 2020 [Video file]. retrieved from http://fr.itweb.tv/Next-Two-Renault-lancera-sa-voiture-robot-avant-2020_v1328.html

Browne, M. W., \& Cudeck, R. (1989). Single sample cross-validation indices for covariance structures. Multivariate Behavioral Research, 24(4), 445-455.

Cestac, J. \& Delhomme, P. (Ed) (2012). European road users' risk perception and mobility, The SARTRE 4 survey, Lyon France: Public Imprim.

Cestac, J., Paran, F., \& Delhomme, P. (2011). Young drivers' sensation seeking, subjective norms and perceived behavioral control and their roles in predicting speeding intention: How risk-taking motivations evolve with gender and driving experience. Safety Science, 49, 424-432.

Davis, F. D. (1989). Perceived usefulness, perceived ease of use, and user acceptance of information technology. MIS quarterly, 13(3),319-340.

Davis, F.D., Bagozzi, R.P., \& Warshaw, P.R. (1989). User Acceptance of Computer Technology: A Comparison of Two Theoretical Models, Management Science, 35, 982-1003.

Delhomme, P. (2002). Croyances des jeunes automobilistes en matière de vitesse. Rapport final. Convention DSCR-INRETS N00/010/T-étude Nº.

Delhomme, P., \& Meyer, T. (2002, 2ème édition). Les projets de recherche en psychologie sociale: méthodes et techniques. La recherche en psychologie sociale. Projets, méthode et techniques. Paris : Armand Colin, Coll. Cursus. 
Delhomme, P., Verlhiac, J.-F., \& Martha, C. (2009). Are drivers' comparative risk judgments about speeding realistic? Journal of Safety Research, 40, 333-339.

Desmond, P.A., \& Hoyes, T.W. (1996). Workload variation, intrinsic risk and utility in a simulated air traffic control task: evidence for compensatory effects. Safety Science, 22, 87-101.

de Waard, D., van der Hulst, M., Hoedemaeker, M., \& Brookhuis, K. A. (1999). Driver behavior in an emergency situation in the Automated Highway System. Transportation Human Factors, 1, 67-82.

Eagly, A. H., \& Chaiken, S. (1993). The psychology of attitudes. Orlando, FL: Harcourt Brace Jovanovich.

European Commission. (2011). WHITE PAPER: Roadmap to a Single European Transport AreaTowards a competitive and resource efficient transport system. COM (2011), 144.

Fancher, P., Ervin, R., Sayer, J., Hagan, M., Bogard, S., Bareket, Z., Mefford, M., \& Haugen, J. (1998). Intelligent cruise control field operation test. Final Report. NHTSA Report No. DOT HS 808849.

Fishbein, M., \& Ajzen, I. (1975). Belief, attitude, intention and behavior: An introduction to theory of research. Reading, MA: Addison-Wesley.

Fuller, R. (2005). Towards a general theory of driver behaviour. Accident Analysis \& Prevention, 37(3), 461-472.

Guizzo, E. (2011). How google's self-driving car works. IEEE Spectrum Online, October, 18.

Hancock, P.A., \& Parasuraman, R. (1992). Human Factors and Safety in the Design of Intelligent Vehicle-Highway Systems (IVHS). Journal of Safety Research, 23, 181-198.

Hancock, P.A., \& Verwey, W.B. (1997). Fatigue, workload and adaptive driver systems. Accident Analysis and Prevention, 29, 495-506.

Hoedemaeker, M., \& Brookhuis, K.A. (1998). Behavioural adaptation to driving with an adaptive cruise control (ACC). Transportation Research Part F, 1, 95-106.

Hoedemaker, M., \& Kopf, M. (2001). Visual sampling behavior when driving with adaptive cruise control. In Proceedings of the $9^{\text {th }}$ International Conference on Vision in vehicles Australia, August 1922, 2001.

Hu, L.T. \& Bentler, P.M. (1999). Cut-off criteria for fit indexes in covariance structure analysis. Conventional criteria versus new alternatives. Structural Equation Modeling, 6(1), 1-55.

Jamson, A. H., Merat, N., Carsten, O. M., \& Lai, F. C. (2013). Behavioural changes in drivers experiencing highly-automated vehicle control in varying traffic conditions. Transportation Research Part C: Emerging Technologies, 30, 116-125.

Jonah, B. A., Thiessen, R., \& Au-Yeung, E. (2001). Sensation seeking, risky driving and behavioral adaptation. Accident Analysis \& Prevention, 33(5), 679-684.

Jöreskog, K. G., \& Sörbom, D. (1989). LISREL 7: A guide to the program and applications (Vol. 2). Chicago: Spss. 
Kaber, D. B., \& Endsley, M. R. (1997). Out-of-the-loop performance problems and the use of intermediate levels of automation for improved control system functioning and safety. Process Safety Progress, 16(3), 126-131.

Lefeuvre, R., Bordel, S., \& Guingouain, G. (2008). Sentiment de contrôle et acceptabilité sociale a priori des aides à la conduite. Le travail humain, 71(2), 97-135.

Leggett, C., Kleckner, N., Boyle, K., Duffield, J., \& Mitchell, R. (2003). Social desirability bias in contingent valuation surveys administered through in-person interviews. Land Economics, 79(4), 561-575.

Laurencin, J.-P., Hoffman, J., Forest, F., \& Ruffieux, B. (2004). Retrieved May 19, 2009, from www.mshalpes.prd.fr.Website:www.mshalpes.prd.fr/luce/documents/presentations/Axe4_Acceptab ilite_Forest_19052004.ppt.

Maccoby, E., \& Maccoby, N. (1954). The Interview: A Tool of Social Science. Handhook of Social Psychology, I, 449-487.

Maltz, M., Sun, H., Wu, Q., \& Mourant, R. (2004). In-vehicle alerting system for older and younger drivers: Does experience count? Transportation Research Record: Journal of the Transportation Research Board, 1899(1), 64-70.

Montag, I., \& Comrey, A.L. (1987). Internality and externality as correlates of involvement in fatal driving accidents. Journal of Applied Psychology, 72, 339-343.

Moray, N., Inagaki, T., \& Itoh, M. (2000). Adaptive Automation, Trust, and Self-Confidence in Fault Management of Time-Critical Tasks. Journal of Experimental Psychology: Applied, (6)-1, 44-58.

National Highway Traffic Safety Administration. (2013). Preliminary Statement of Policy Concerning Automated Vehicles System. Washington, DC.

Nilsson, L. (1995). Safety effects of adaptive cruise control in critical traffic situations. In Proceedings of the Second World Congress on Intelligent Transport Systems: Vol. 3 (Tokyo: Vehicle, Road and Traffic Intelligence Society), 1254-1259.

Özkan, T., Lajunen, T., \& Kaistinen, J. (2005). Traffic locus of control, driving skills, and attitudes towards in-vehicle technologies (ISA and ACC). In Proceedings of the 18th international cooperation on theories and concepts in traffic safety (ICTCT), Helsinki, Finland.

Parasuraman, R. \& Riley, V. A. (1997). Humans and automation: use, misuse, disuse, abuse, Human Factors, 39(2), 230-253.

Parasuraman, S., Singh, I. L., Molloy, R., \& Parasuraman, R. (1992). Automation-related complacency: A source of vulnerability in contemporary organizations. IFIP Transactions A-Computer Science and Technology, 13, 426-432.

Robson, C. (1993). Real world research. A resource for social scientists and practitioner-researchers. Oxford UK and Cambridge USA, Backwell. 
Riley, V. (1994). Human use of Automation. Unpublished doctoral dissertation, University of Minnesota, Minneapolis.

Rotter, J. B. (1966). Generalized expectancies for internal versus external control of reinforcement. Psychological monographs: General and applied, 80(1), 1-28.

Rudin-Brown, C. M., \& lan Noy, Y. (2002). Investigation of behavioral adaptation to lane departure warnings. Transportation Research Record: Journal of the Transportation Research Board, 1803(1), 30-37.

Rudin-Brown, C.M., \& Parker, H.A. (2004). Behavioural Adaptation to Lane Departure Warning. Transportation Research Record, 1803, 30-37.

Saad, F., Hjälmdahl, M., Cañas, J., Alonso, M., Garayo, P., Macchi, L., Nathan, F., Ojeda, L., Papakostopoulos, V., Panou, M., \& Bekiaris, E. (2004). Literature review of behavioural effects. Rapport AIDE.

Saad, F., \& Villame, T. (1996). Assessing new driving support systems: contribution of an analysis of drivers' activity in real situations. Proceedings of Third Annual World Congress on Intelligent Transport System (CD Rom).

Stanton, N.A., \& Marsden, P. (1996). From fly-by-wire to drive-by-wire: Safety implications of automation in vehicles. Safety Science, 24, 35-49.

Stanton, N.A., \& Young, M.S. (1998). Vehicle automation and driving performance, Ergonomics, 41-7, 1014-1028. doi.org/10.1080/001401398186568

Stanton, N.A., \& Young, M.S. (2005). Driver behaviour with adaptive cruise control. Ergonomics, 48(10), 1294-1313. doi:10.1080/00140130500252990

Stanton, N.A., Young, M.S. \& McCaulder, B. (1997). Drive-by-wire: The case of driver workload and reclaiming control with Adaptive Cruise Control. Safety Science, 27, 149-159.

Stanton, N.A., Young, M.S., Walker, G.H., Turner, H., \& Randle, S. (2001). Automating the driver's control tasks. International Journal Of Cognitive Ergonomics, 5(3), 221-236. doi:10.1207/S15327566IJCE0503_5.

Taubman, O., Mikulincer, M., \& Iram, A. (1996). The cognitive, motivational and emotional system of driving. Research report, Department of Casualties and Road Safety of the Israeli Army, Israel.

Terrade, F., Pasquier, H., Reerinck-Boulanger, J., Guingouain, G. \& Somat, A. (2009). L'acceptabilité sociale: la prise en compte des déterminants sociaux dans l'analyse de l'acceptabilité des systèmes technologiques. Le Travail Humain, 72, 383-395.

van der Laan, J.D., Heino, A., \& de Waard, D. (1997). A simple procedure for the assessment of acceptance of advanced transport telematics. Transportation Research Part C, 5, 1-10.

van Dijke, J. P., \& van Schijndel, M. (2012). CityMobil, advanced transport for the urban environment. Transportation Research Record: Journal of the Transportation Research Board, 2324(1), 29-36. 
van Driel, C. J. G., Hoedemaeker, M., \& Van Arem, B. (2007). Impacts of a Congestion Assistant on driving behaviour and acceptance using a driving simulator. Transportation Research Part F: Traffic Psychology and Behaviour,10(2), 139-152.

Venkatesh, V., Morris, M. G., \& Ackerman, P. L. (2000). A Longitudinal Field Investigation of Gender Differences in Individual Technology Adoption Decision Making Processes, Organizational Behavior and Human Decision Processes, 83(1), 33-60.

Ward, N.J., Fairclough, S. \& Humphreys, M. (1995). The effect of task automatisation in the automotive context: a field study of an autonomous intelligent cruise control system. Paper presented at International Conference on Experimental Analysis and Measurement of Situation Awareness, 1 November, Daytona Beach, FL.

Ward, N.J., Humphreys, M., \& Fairclough, S. (1996). A field study of behavioural adaptation with an autonomous intelligent cruise control system. Handbook of the International Conference on Traffic and Transport Psychology, 22-25 May, Valencia, Spain, 15-19.

Wiener, E. L. (1981). Complacency: Is the term useful for air safety? In Proceedings of the 26th Corporate Aviation Safety Seminar, 117, Denver: Flight Safety Foundation, Inc.

Yagil, D. (2001). Reasoned action and irrational motives: A prediction of drivers' intention to violate traffic laws. Journal of Applied Social Psychology, 31, 720-740.

Young, M. S., \& Stanton, N. A. (1997). Automotive automation: Investigating the impact on drivers' mental workload. International Journal of Cognitive Ergonomics, 1(4), 325-336.

Young, M. S., \& Stanton, N. A. (2007). What's skill got to do with it? Vehicle automation and driver mental workload. Ergonomics, 50(8), 1324-1339. doi:10.1080/00140130701318855.

Zuckerman, M. (1994). Behavioural Expressions and Biosocial Bases of Sensation Seeking. Cambridge: University of Cambridge Press. 


\section{Tables}

Table 1

ANOVA

\begin{tabular}{lcccc}
\hline & $M_{\odot}^{\Uparrow}$ & $M_{+}$ & $F$ & $\eta^{2}$ \\
\hline Intention to use & 5.01 & 4.18 & $20.6^{*}$ & .05 \\
Intention to buy & 4.03 & 3.27 & $14.2^{*}$ & .03 \\
Willingness-to-pay & 1877 & 1468 & n.s. & - \\
Age & 43.75 & 38.05 & $12.8^{*}$ & .03 \\
Interest in impaired driving & 5.31 & 4.92 & n.s. & - \\
Contextual acceptability & 4.62 & 3.97 & $22.3^{*}$ & .05 \\
DRSS & 3.19 & 2.63 & $24.7^{*}$ & .06 \\
Attitudes & 5.04 & 4.31 & $24.5^{*}$ & .06 \\
\hline
\end{tabular}

Note $: * p<.001$, DRSS $=$ Driving Related Sensation Seeking

Table 2

Correlations $(N=421)$

\begin{tabular}{|c|c|c|c|c|c|c|c|c|c|c|c|c|}
\hline & $M$ & $S D$ & 1 & 2 & 3 & 4 & 5 & 6 & 7 & 8 & 9 & 10 \\
\hline 1. Intention to use & 4.46 & 1.84 & & & & & & & & & & \\
\hline 2. Intention to buy & 3.54 & 1.98 & $.79 * *$ & & & & & & & & & \\
\hline 3. Willingness-to-pay & 1624 & 2124 & $.32 * *$ & $.39 * *$ & & & & & & & & \\
\hline 4. Gender & - & - & $-.22 * *$ & $-.18 * *$ & -.09 & & & & & & & \\
\hline 5. Age & 40.23 & 15.86 & .08 & .09 & $-.19 * *$ & $-.18^{* *}$ & & & & & & \\
\hline 6. Interest in impaired driving & 5.03 & 2.00 & $.37 * *$ & $.27 * *$ & $.15^{* *}$ & -.10 & .09 & & & & & \\
\hline 7. Contextual acceptability & 4.16 & 1.39 & $.69 * *$ & $.63^{* *}$ & $.26 * *$ & $-.23 * *$ & $.17 * *$ & $.36^{* *}$ & & & & \\
\hline 8. DRSS & 2.84 & 1.13 & $.15^{* *}$ & $.12 *$ & $.10^{*}$ & $-.24 * *$ & $-.23 * *$ & $.10^{*}$ & .06 & & & \\
\hline 9. Attitudes & 4.56 & 1.49 & $.80^{* *}$ & $.76^{* *}$ & $.34 * *$ & $-.24 * *$ & .07 & $.38 * *$ & $.71 * *$ & $.12 *$ & & \\
\hline 10. Driving Externality & 5.80 & 0.74 & -.05 & -.01 & .01 & .06 & $.13^{* *}$ & .05 & -.02 & $.13^{* *}$ & .02 & \\
\hline 11. Driving Internality & 6.40 & 3.70 & .08 & $.15^{* *}$ & .05 & -.05 & $.23^{* *}$ & .06 & $.12 *$ & -.04 & $.12 *$ & .01 \\
\hline
\end{tabular}

Note: $* p<.05, * * p<.01, * * * p<.001$, DRSS = Driving Related Sensation Seeking 
Table 3

Hierarchical linear regression of the intention to use a fully automated car $(N=389)$

\begin{tabular}{lcccc}
\hline & $\Delta R^{2}$ & Step 1 & Step 2 & Step 3 \\
\hline Step 1 & .05 & & & \\
Gender & & $-.16^{* *}$ & -.04 & .02 \\
Age & & .09 & -.02 & .02 \\
DRSS & & $.14^{*}$ & $.09 *$ & $.07 *$
\end{tabular}

Step 2

.43

Interest in impaired driving

$.11 * * \quad .04$

Contextual acceptability

$.63 * * * \quad .24 * * *$

Step 3

.19

Attitude

$.62 * * *$

Note: $* p<.05, * * p<.01, * * * p<.001$, gender is a dummy variable, coded Male $=1$ and Female $=2$, DRSS $=$ Driving Related Sensation Seeking 